\title{
Thermo-economic Assessment of the Possible Desalination Processes for the Second Block of Bushehr Nuclear Power Plant
}

\author{
Khashayar Sadeghi ${ }^{1}$, Seyed Hadi Ghazaie ${ }^{1}$, Ekaterina Sokolova ${ }^{1}$, Evgeniy Fedorovich ${ }^{1}$, and Amirsaeed Shirani ${ }^{2}$ \\ ${ }^{1}$ Peter the Great St. Petersburg Polytechnic University, Polytechnicheskaya str., 195251 Russian Federation \\ ${ }^{2}$ Shahid Beheshti university of Iran, Faculty of Nuclear Engineering, P.O. Box: 1983963113, Tehran, Iran
}

\begin{abstract}
Nowadays, the problem of supplying fresh water to scarcer regions of the world is still acute. The seawater desalination has been touted as the main solution of closing the water gap in the Middle East and North Africa. However, seawater desalination is expensive and energy-intensive and influences the environment, extremely. Using nuclear power is a viable alternative energy resource to decrease the set of problems of consuming fossil fuels in the desalination plants. Iran, which is located in the arid belt of the eastern hemisphere, as a member state of IAEA (International Atomic Energy Agency) has announced his interest in the implementation of dual-purpose nuclear desalination in the existing nuclear power plant of the country. The Bushehr nuclear power plant is the first commercial nuclear reactor in the Middle East and can be used as a multi-purpose atomic complex to meet the demand for energy and supply of water to arid regions in the south of the country. This paper performs a thermo-economic assessment study for different desalination strategies in the second block of Bushehr NPP.
\end{abstract}

\section{Introduction}

For decades, one of the most important and costly issues of world governments is the water scarcity. The factors such as growing the population of the world during past 50 years, lack of proper management of water for agricultural purposes, which uses more than $70 \%$ of total available fresh water of the earth, fresh water contamination by human and environmental factors, climate changes of the earth and reduction of groundwater and natural resources have exacerbated the shortage of water in the residential regions. The international statistics present that the countries in the Middle East and north of Africa (MENA) more than other countries are at the risk of water shortage. According to the various measures about 14 countries of MENA are among the top 20 water-scarce countries. By considering the mentioned factors the fresh water outlook is expected to get worse in the future. To offer just one example, the United Nations (UN) experts have announced that the amount of available fresh water per capita in the Middle East will be cut in half by 2025 [1]. Similar to all the countries in the Middle East Iran also is located in the arid and semi-arid regions and suffers from fresh water shortage. Despite the fact that the underground and natural water resources and the average rainfall of Iran are in a better position in comparison to most of the MENA countries, the country is heading for the water crisis on a large scale. Iranian consumes about 250 liters of water per day, which is less than the United States (US) citizens who consume about 400 liters of fresh water per day, but the problem is the absence of rich US water resources in Iran. If the steps to manage fresh water resources through the reduction of water use and the development of existing resources cannot meet fresh water demand, the technology of seawater desalination can be considered as the best method to meet the increasing demands of fresh water [2].

By considering the geographical location of Iran, where is bounded by the Caspian Sea, the Persian Gulf, and the Oman Sea, the seawater desalination can be supposed as the main and most beneficial strategy for supplying the demand fresh water of the country. The northern regions of Iran, where are located near to the Caspian Sea, in comparison to the southern regions have a more acceptable situation, in the case of the fresh water resources. Currently, about 22 million cubic meters of seawater desalination is producing in the Persian Gulf daily that Iran's share of this amount is only 200 thousand cubic meters.

The government of Iran believes that taking advantage of the vast coastline in the south of the country as well as peaceful nuclear knowledge can increase Iran's share of the produced fresh water from the Persian Gulf. Bushehr NPP as the first commercial nuclear reactor in the country, which includes 4 phases, can be included the establishment of a large-scale desalination plant. The first block of the NPP has been operated since May 2011. Furthermore, the implementation of the foundation-laying of the second phase has been started since 2017 .

Numerous studies have been carried out on combining nuclear reactors with desalination plants, including technical aspects [3, 4], safety consideration 
[5], and economic evaluation [6-8] of nuclear desalination. In addition, the IAEA has been published various feasibility studies on nuclear desalination of seawater with the participation of interested Member States. Recently, Dincer et al. [9] have carried out a cost assessment of various nuclear-based desalination systems using the Desalination Economic Evaluation Program (DEEP). Amani et al. [10] have presented a Techno-economic analysis of the Latest advances nuclear desalination system. Salah et al. [11] have explored the possibility of using the various types of nuclear power plants as the source of energy in the desalination units in the MENA region.

The main goal of this research is to compare the five different types of desalination systems namely MED, RO (Reverse Osmosis), MSF (Multi-Stage Desalination), MSF + RO, and MED + RO, coupling with the second block of Bushehr nuclear power plant. The economic and thermodynamic calculations presented in this paper are based on the utilization of the Desalination economic evaluation program (DEEP 5) software and Desalination Thermodynamic Optimization Program (DE-TOP), respectively [12]. In this paper, as the first step, a brief description of possible desalination methods will be presented. The aim here is to investigate the advantages and disadvantages of various options in the case of the technical and economic aspects. After reviewing the desalination methods, the technical specifications of the Bushehr nuclear power plant will be presented. A brief description of DEEP and DE-TOP programs are considered as the next step of this research, and finally, the simulated scheme of Bushehr nuclear power plant combined with the desalination units and obtaining the thermo-economic results as the main goal of the paper will be considered.

\section{Method}

\subsection{A brief overview of commercial desalination technologies}

The seawater desalination in the large-scale is mainly carried out by one of the following methods: distillation and membrane. The distillation methods, which also are known as the thermal desalination systems, are divided into two major groups, namely MSF and MED. The primary techniques of membrane processes are reverse osmosis and electrodialysis, however, reverse osmosis is more useful on the industrial scale. The main types of consumed energy in the MSF and MED plants are both thermal and electrical. These types of plants can treat very salty water (to $70000 \mathrm{mg} / \mathrm{l}$ ) to produce practically pure water having about 5-25 ppm TDS [10].

The hybrid method is an effective way to improve the performance of large-scale desalination plants. This method cannot be considered as an independent technology. The hybrid scheme is based on applying at least two different desalination technologies in a largescale plant. In figure 1 is depicted as an example of the simple hybrid scheme. In the simple option, the thermal unit is completely independent of the RO unit and just the rejected water or produced water can be passed through the same pipes $[13,14]$.

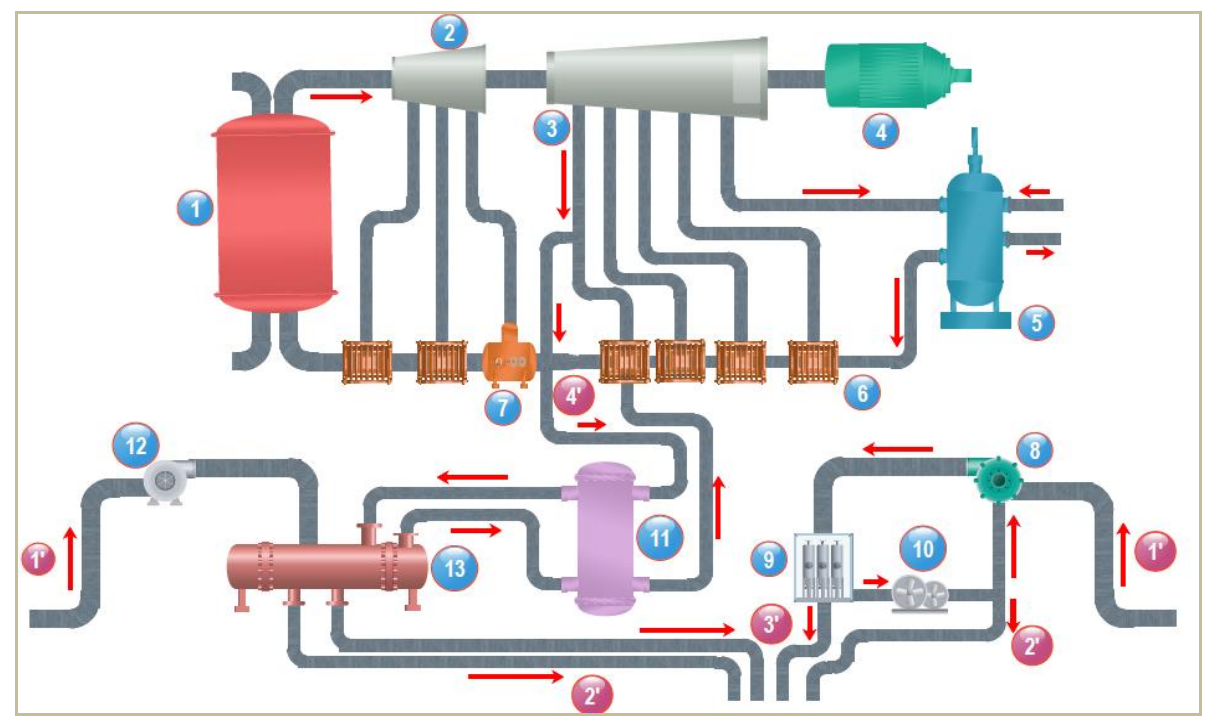

Fig. 1. Typical simple hybrid desalination plant combined with Bushehr Nuclear Power Plant (II)

\subsection{The second block of Bushehr nuclear power plant}

The Bushehr (II) NPP site is located on the coastal plain, in the north of the Persian Gulf near to the first unit of this complex. The construction of the second block of the Bushehr nuclear power plant in Iran with Russian participation has been started since 2017 . The power unit includes a reactor unit with a VVER-1000 (coolant, moderator-light water) type reactor and a turbine unit that serves as a generator drive. The thermal circuit is a dual-circuit. The first circuit contains a radioactive coolant (light water) and consists of a heterogeneous thermal neutron reactor, four main circulation loops, and a steam generator. The second circuit is non-radioactive and consists of the cold section of the steam generator, the main steam pipelines, turbine building, auxiliary 
equipment, and related systems such as deaerator, preheaters of feed water to the steam generators. The main operating parameters of the Bushehr (II) NPP are listed in Table 2.

Table 1. Details information of Fig 1

\begin{tabular}{|c|c|c|c|}
\hline $\begin{array}{c}\text { Number of } \\
\text { equipment } \\
\text { or pipeline }\end{array}$ & description & $\begin{array}{c}\text { Number of } \\
\text { equipment } \\
\text { or pipeline }\end{array}$ & description \\
\hline 1 & $\begin{array}{c}\text { Steam } \\
\text { generator }\end{array}$ & 9 & RO unit \\
\hline 2 & HP turbine & 10 & $\begin{array}{c}\text { Energy } \\
\text { recovery } \\
\text { system }\end{array}$ \\
\hline 3 & LP turbine & 11 & $\begin{array}{c}\text { Intermediate } \\
\text { loop }\end{array}$ \\
\hline 4 & generator & 12 & pump \\
\hline 5 & condenser & 13 & $\begin{array}{c}\text { Thermal } \\
\text { desalination } \\
\text { plant }\end{array}$ \\
\hline 6 & preheater & $1^{\prime}$ & feed water \\
\hline 7 & deaerator & $2^{\prime}$ & $\begin{array}{c}\text { Rejected } \\
\text { water }\end{array}$ \\
\hline 8 & $\begin{array}{c}\text { High- } \\
\text { pressure } \\
\text { pump }\end{array}$ & $3^{\prime}$ & Fresh water \\
\hline
\end{tabular}

\subsection{Bushehr NPP as a cogeneration plant:}

Iran is among the 5 top major energy-rich countries. The country ranks first in the world in terms of natural gas reserves and third in terms of oil reserves. In the last decade, an increase (about 50\%) in primary total energy consumption has appeared in Iran. Currently, the main source for supplying the required energy is fossil resources. However, the long-term energy strategy of the country is the reduction of fossil fuel consumption as much as possible. Iran has over 50 years of experience in seawater desalination and ranks 10th in the world in fresh water production. On the other hand, most of the existing water desalination plants use non-renewable fuels as their primary energy sources [15]. Consequently, the government of Iran is investigating the possible alternative resources of energy such as nuclear energy for using in the desalination water plants to ensure the sustainable provision of water supply to the region into the future [16]. By considering the location of the Bushehr atomic complex, which is in proximity to the Persian Gulf, the best option is to combine a large-scale desalination plant with different blocks of the complex.

\subsection{Thermo-economic assessment:}

In the last few years, there has been a growing interest to decrease the cost of nuclear desalination in both industrial and developed countries. Large-scale seawater desalination cost in some regions in the world is less than $\$ 0.5$ per cubic meter, while in some other regions it would have to be around $\$ 1$ per cubic meter to access the same system. Although seawater desalination is an expensive process, the cost of desalination, particularly $\mathrm{RO}$, is decreasing.
Table 2. Main design parameters of Bushehr (II) nuclear

\begin{tabular}{|l|c|}
\multicolumn{2}{c}{ power plant } \\
\hline Parameter & Value \\
\hline Reactor nominal thermal power & $3012 M W_{t h}$ \\
\hline Main steam pressure & 58.84 bar \\
\hline reactor type & VVER \\
\hline Coolant & Light water \\
\hline Main steam temperature & $274.4^{\circ} \mathrm{C}$ \\
\hline Design temperature & $350^{\circ} \mathrm{C}$ \\
\hline Number of steam generators & 4 \\
\hline Cooling water intake & From Gulf \\
\hline Number of the fuel assembly & 163 \\
\hline Number of fuel rods in FA, pcs & 311 \\
\hline Number of high-pressure turbines & 1 \\
\hline Number of low-pressure turbines & 3 \\
\hline Number of preheaters & 7 \\
\hline The lifetime of the reactor & 40 year \\
\hline
\end{tabular}

The main reasons for cost reduction are: 1- The cost of the membrane has dropped considerably. 2- Material improvements and process innovation. 3- Technological developments and applying them in the equipment of the desalination plant. Hence, before designing a desalination unit in the country, all the possible ways of decreasing the total cost should be considered. Furthermore, the Influential parameters on the total cost of the plant should be included in the evaluations. There are several parameters, which are affecting the cost of the desalination unit's productions, directly. The interest rate of the country, preheating the feed water of the RO plant, feed water quality and energy consumption are some of the most important factors affecting the total cost of the desalinated water. The interest rate is a specific value in each country, which is changed by the economic conditions and policy. Currently, the interest rate of Iran is about $15 \%$ and according to the economic conditions of the country such as the availability of money in a country's financial system, it can be predicted that the interest rate of the country will be decreased, continuously. The preheating of feed-water of $\mathrm{RO}$ systems is a possible method to reduce the specific power consumption of desalination and the total cost of the fresh water. By increasing the temperature of feed water, the viscosity decreases and consequently, the RO membrane becomes more permeable. The best ways to preheat the feed water are using the waste heat in the condenser of the NPP or using the rejected heat from the thermal desalination plant. The salinity of inlet water to the desalination equipment is one of the main factors for setting the operating conditions of the RO unit. The salinity of desalination's feedwater depends on the regional location and the type of water source. The Persian Gulf is among the most saline locations on Earth. The average salinity of the Arabic parts of the Gulf is about 45000 while this parameter for the north part of the Gulf, which ends to coasts of Iran, is about 42,000 ppm. This high value has forced the Gulf countries to develop desalination units based on the thermal methods $[17,18]$. 


\subsection{Description of modeling tools:}

The objective of this paper is to analyze and compare the thermo-economic aspects of various desalination options for the second block of the Bushehr nuclear power plant using the DEEP and DE-TOP programs. The DE-TOP program is used as the simulator of the second block of the NPP. This program by molding all the thermodynamic parameters of the plant can evaluate the total efficiency of the co-generation plant after coupling with a thermal desalination unit. In addition, DE-TOP calculates energy and exergy flows of the co-generation system and produces detailed reports for plant performance. Furthermore, by using the DE-TOP, the possible points for steam extraction can be defined. DETOP has a user-friendly interface and allows a better understanding of the system. In order to simulate the second cycle of the power plants, the program needs some initial inputs as the first step. However, the important inputs parameters such as thermal capacity, live steam conditions, the pressure of preheaters and cooling water temperature can be modified in the next steps of running the program by the user.

The next part of the process for thermoeconomic assessment is running the DEEP program. In the DEEP program, a nuclear power plant can be modeled by adjustment of input parameters including net output power, thermodynamic parameters of the site and economic parameters such as interest rate. It should be noted that the DEEP program not only can simulate the nuclear power plants (light water reactors) but also fossil fuels based power plants. Output includes the total and specific cost of the produced water and the cost of the produced power with all the possible details. It can be stated that the main disadvantage of the DEEP program appears during modeling the hybrid schemes.

Although in the DEEP program the possibility of applying the hybrid methods is defined, nonetheless this option includes just one hybrid model (simple model), and the integrated hybrid models cannot be simulated by the program. To overcome this difficulty, it is necessary to rewrite the program and the possibility of performing various schemes of the hybrid desalination should be added. Developing a new code based on the methodology of the DEEP has three main advantages: 1The weak point of the program about hybrid options will be covered up. 2- The effects of the volume of the intake's water can be applied to the total cost of the produced water. 3- The possibility of the economic evaluation of solar power plants or small modular reactors (SMRs), coupled with the desalination plants can be added. However, developing a new program for thermo-economic assessment is beyond the scope of this paper and can be considered as a suggestion for future works. In the current study, the calculations are based on the simple hybrid scheme and with the purpose of making analyze simpler, except for the particular properties of the second block of Bushehr NPP, all other technical and economic input parameters were assumed to be the same as the default of DEEP database. In table 3 the necessary input parameters of the DEEP program are listed.

\section{Results}

\subsection{Thermodynamic aspects of the desalination unit in the second block of the Bushehr complex}

In this section, the simulation of the second cycle of the Bushehr (II) NPP, coupled with the thermal desalination unit has been performed. To simulate nuclear power plants in DE-TOP, the user should use the input parameters, which are listed in Table 3. Figures 2 presents the heat balance obtained as a result of modeling in the DE-TOP software.

The integration of a desalination plant with a nuclear power plant forms a cogeneration system. We expect that the overall efficiency of this installation will be higher than that of a single-purpose power plant. Figure 3 shows the efficiency of the cogeneration Bushehr (II) nuclear power plant for various industries and technologies. It should be noted that the obtained results for each capacity are the average of all possible cases (all possible extraction points in the second cycle). According to this figure, the efficiency of a cogeneration plant with constant capacity using MSF technology is greater than that of MED technology. In addition, by increasing the capacity of the desalination plant, the efficiency of the cogeneration system increases [19].

Table 3. The input parameters of the DEEP program for Bushehr (II) nuclear power plant

\begin{tabular}{|c|c|c|}
\hline $\begin{array}{l}\text { Desalination plant } \\
\text { specifications }\end{array}$ & unit & Value \\
\hline $\begin{array}{l}\text { Total desalination plant } \\
\text { capacity }\end{array}$ & $\mathrm{m}^{3} /$ day & variable \\
\hline Total dissolved solids & ppm & 42000 \\
\hline $\begin{array}{c}\text { Feedwater inlet } \\
\text { temperature for reverse } \\
\text { osmosis }\end{array}$ & ${ }^{0} \mathrm{C}$ & 25 \\
\hline $\begin{array}{l}\text { The lifetime of the } \\
\text { desalination system }\end{array}$ & year & 20 \\
\hline Interest rate & $\%$ & 18 \\
\hline Discount rate & $\%$ & 6 \\
\hline Electricity selling price & $\$ / M W h$ & 100 \\
\hline Water selling price & $\$ / \mathrm{m}^{3}$ & 1.9 \\
\hline
\end{tabular}




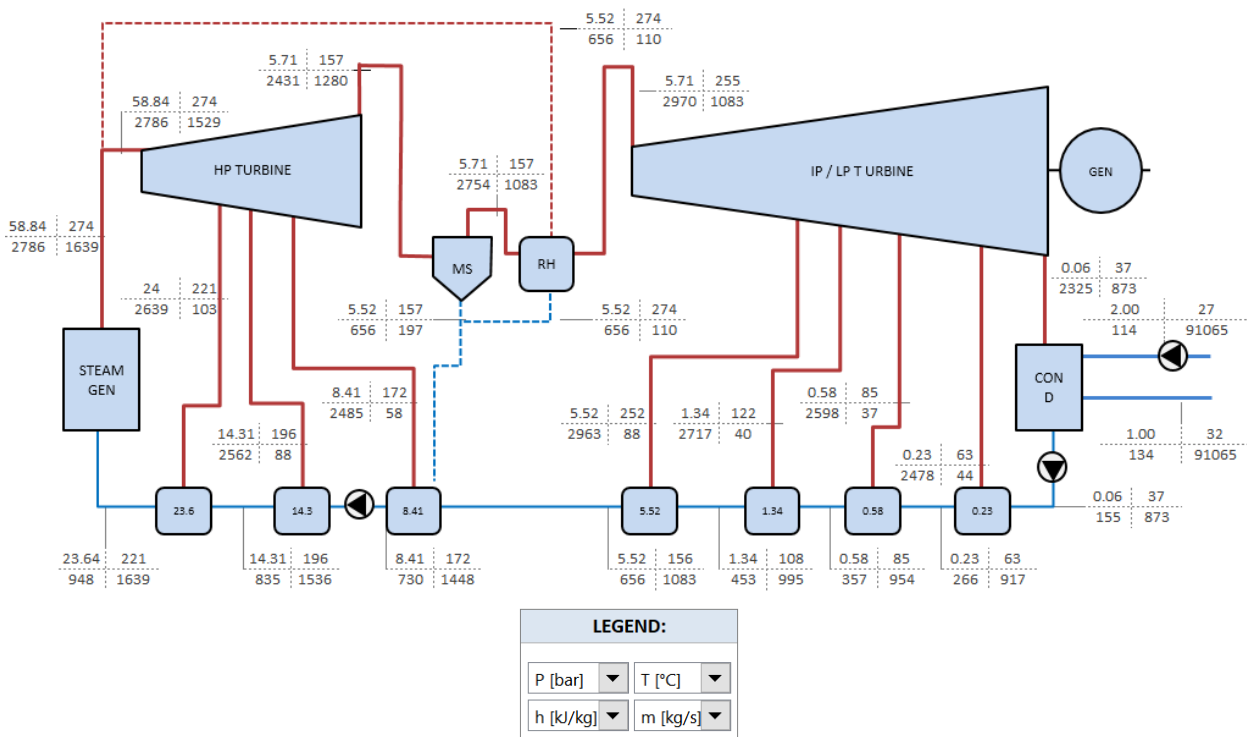

Fig. 2. Heat balance obtained as a result of simulation in the DE-TOP software package

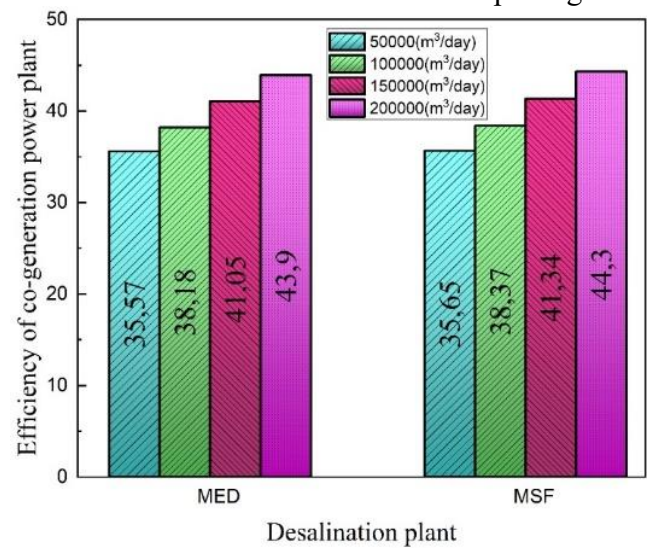

Fig. 3: Cogeneration efficiency of Bushehr (II) for various technologies and capacities

\subsection{Economic aspects of the desalination unit in the second block of the Bushehr complex}

In this section, analyzing the economic aspects of the desalination plant in the second unit of the Bushehr NPP has been conducted. The cost of the produced fresh water is estimated using the DEEP program, which was presented in Section 4.1. The study uses various desalination methods: MSF, MED, RO, and hybrid (simple hybrid scheme). Firstly, the economic assessment of coupling the Bushehr (II) NPP with 3 possible seawater desalination technologies, which were described in the preview sections, is presented. The obtained results for each case are based on the initial data, which were given in table 3 . However, some parameters, such as interest rate and capacity, are considered as variable parameters to demonstrate the behavior of the outputs. In Table 4 all the important economic results for various desalination technologies with the capacity of $150000\left(\mathrm{~m}^{3} /\right.$ day $)$ are listed.

The total cost of desalinated water for various technologies, with respect to the various total capacity, is presented in Figure 4. The results show that the total cost of the produced water by RO technology is less than the total cost using thermal technologies in all the capacities. Due to the fact that the MSF method uses much more energy than the MED method (it can be seen also in Table 4), hence the total cost of the MSF is more than the MED plant (almost 60 to $70 \%$ ).

As discussed in previous chapters, the interest rate is one of the most important parameters affecting the cost of the water. Considering the concept of this parameter, one should expect that with an increase in the interest rate, the total cost also increases. Fig. 5 shows the effect of changes in interest rates on the total cost of desalinated water for various methods, which corresponds to a capacity of $50000 \mathrm{~m}^{3} /$ day. Similar graphics can be drawn for any capacity, but since the tendency of changes for all the capacities is the same, only $50000 \mathrm{~m}^{3}$ / day has been chosen. 
Table 4. Economic results of various desalination technologies for the capacity of $150000\left(\mathrm{~m}^{3} /\right.$ day $)$

\begin{tabular}{|c|c|c|c|}
\hline & \multicolumn{3}{|c|}{ Technology } \\
\hline & RO & MED & MSF \\
\hline \multicolumn{4}{|l|}{$\begin{array}{l}\text { The capital cost of the } \\
\text { desalination plant }\end{array}$} \\
\hline $\begin{array}{l}\text { The basic cost of the } \\
\text { desalination plant }\left(\$ / \mathrm{m}^{3}\right)\end{array}$ & 0.271 & 0.423 & 0.450 \\
\hline $\begin{array}{l}\text { The total cost of the } \\
\text { ownership }\left(\$ / \mathrm{m}^{3}\right)\end{array}$ & 0.013 & 0.021 & 0.022 \\
\hline Contingency cost $\left(\$ / \mathrm{m}^{3}\right)$ & 0.028 & 0.044 & 0.047 \\
\hline $\begin{array}{l}\text { Interest during construction } \\
\left(\$ / \mathrm{m}^{3}\right)\end{array}$ & 0.056 & 0.088 & 0.093 \\
\hline Total capital cost $\left(\$ / \mathrm{m}^{3}\right)$ & 0.370 & 0.577 & 0.613 \\
\hline \multicolumn{4}{|l|}{ Cost of the energy } \\
\hline Thermal energy cost $\left(\$ / \mathrm{m}^{3}\right)$ & 0 & 0.417 & 0.92 \\
\hline Electricity cost $\left(\$ / \mathrm{m}^{3}\right)$ & 0.2591 & 0.143 & 0.19 \\
\hline Total energy cost $\left(\$ / \mathrm{m}^{3}\right)$ & 0.2591 & 0.560 & 1.12 \\
\hline \multicolumn{4}{|l|}{$\begin{array}{l}\text { Operation and Maintenance } \\
\text { Costs }\end{array}$} \\
\hline Management cost $\left(\$ / \mathrm{m}^{3}\right)$ & 0.0040 & 0.0044 & 0.0044 \\
\hline Labor cost $\left(\$ / \mathrm{m}^{3}\right)$ & 0.0162 & 0.018 & 0.018 \\
\hline Material cost $\left(\$ / \mathrm{m}^{3}\right)$ & 0.165 & 0.070 & 0.07 \\
\hline Insurance cost $\left(\$ / \mathrm{m}^{3}\right)$ & 0.020 & 0.031 & 0.033 \\
\hline $\begin{array}{l}\text { Total Operation and } \\
\text { Maintenance Costs Расходы } \\
\left(\$ / \mathrm{m}^{3}\right)\end{array}$ & 0.185 & 0.123 & 0.125 \\
\hline Total annual cost (M\$) & 40.14 & 55.98 & 82.48 \\
\hline The total cost of water $\left(\$ / \mathrm{m}^{3}\right)$ & 0.814 & 1.262 & 1.856 \\
\hline
\end{tabular}

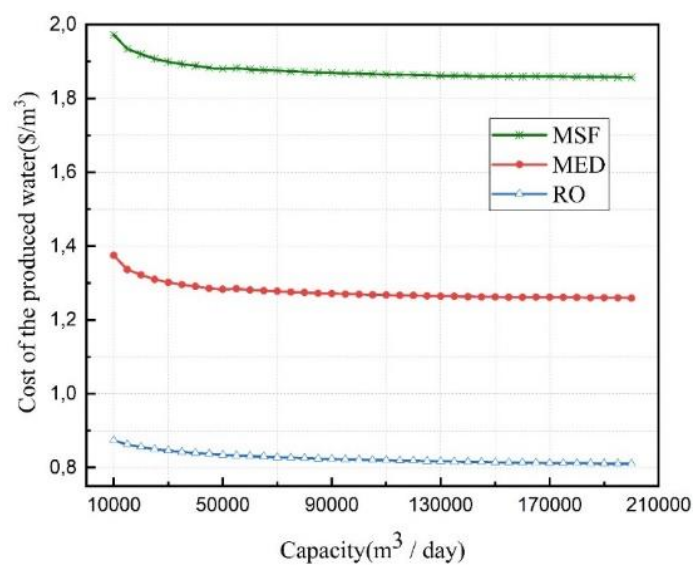

Fig. 4. the total cost of the produced water for various technologies with different total capacities
The next important parameter, which impresses the total cost of the produced water is the levelized energy cost (LEC) in the desalination plant. This parameter depends on the economic condition of each country and also the type of power plant (the cost of the produced energy is the fossil fuels based power plants is different from the produced energy cost of the nuclear power plant). According to the published reports by the Atomic Energy Organization of Iran, the average value for this parameter is about $0.08 \$$ for the first block of the Bushehr complex. In this study, the LEC in all desalination methods also is considered $0.8 \$$. However, it's possible that this value will be changed during the operation time of the power plant. In figure $6(a, b, c)$ the cost of the electricity and thermal energy used in the various desalination plants with respect to various LECs are presented. Furthermore, in figure 6 (c) the comparison between the total cost of the fresh water for various technologies with respect to the variation of the energy cost is demonstrated.

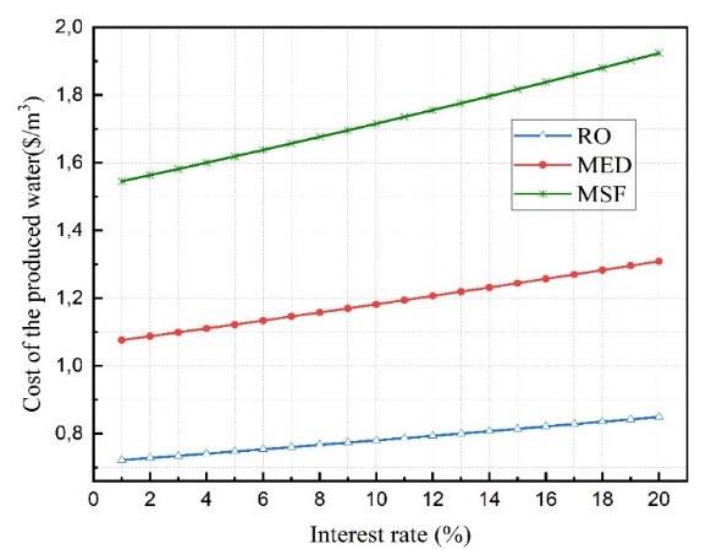

Fig.5. The effect of changing the interest rate on the total cost of the produced water 

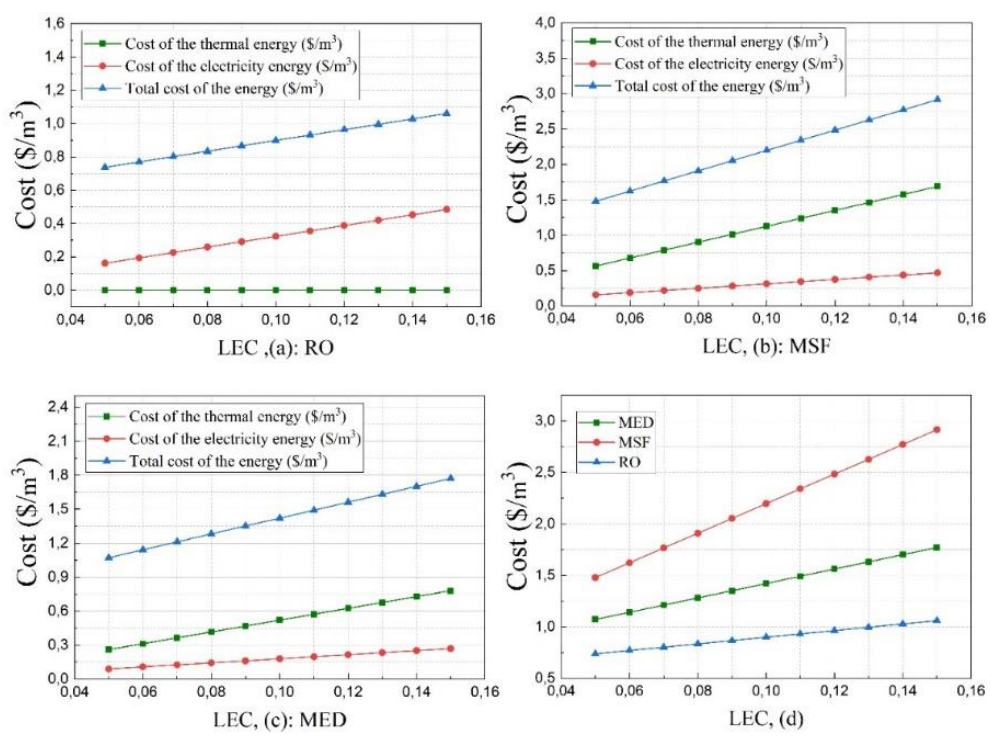

Fig. 6. (a,b,c): the cost of the consumed energy (thermal, electricity and total) for various technologies with respect to the levelized energy cost. Fig. 6. (d): the comparison of the total cost of the produced water for various technology with respect to the different levelized energy coat.

As mentioned in the preview sections, the hybrid scheme is a useful and possible way to increase the efficiency of water plant and also decrease the total cost of the produced water, in comparison to the thermal methods. Figure 7 presents the total cost of the produced water with various capacities using the simple hybrid method. In the simple hybrid case of this study, the amount of total capacity has been divided into two parts, in which the thermal / RO ratio is considered $30 \%$. The thermal method could be either MED or MSF, contingent upon the economic aspects. By comparing the obtained results, which are illustrated in Fig 7 with Fig 4, it can be found that the costs of the hybrid methods are less than the total cost of the thermal methods and also more than the RO method. By considering the advantages of using hybrid methods, it seems that the MED+RO process can be selected as the best choice in terms of costs, among the suggested scenarios. Nonetheless, it is conceivable that our suggested scheme faces a number of industrial limitations of the country, which analyzing them are beyond the scope of this study.

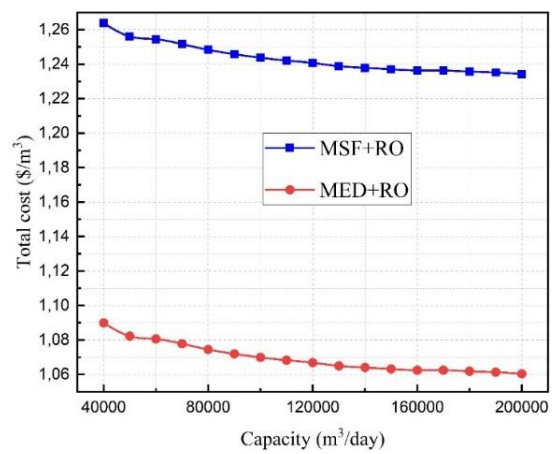

Fig. 7. The total cost of the produced water using the simple hybrid method with respect to the capacity

\section{Discussion}

Iran, as a developing country, has expressed his interest in nuclear desalination and is trying to get involved in developing nuclear reactors and desalination systems. The main goal of this research is analyzing the nuclear desalination in Iran and especially, in the Bushehr complex. Evaluation of the total cost of the different technologies performed by considering the effect of various parameters such as interest rate. The most striking result to emerge from the obtained data is that applying the RO technology in order to produce the fresh water in the Bushehr (II) is more beneficial than the thermal methods in the case of the economic. However, by considering the advantages of hybrid methods, the simple hybrid plant with MED thermal technology can be suggested as the best option. Furthermore, the thermodynamic analysis, which performed by the DETOP program, indicated that the efficiency of cogeneration is more than the efficiency of single-purpose plant in the Bushehr (II) complex.

The produced fresh water in the Bushehr complex can be increased in the next years by installing the new blocks of Bushehr NPP, which already are under the contract. We propose that further research should be undertaken in developing the new desalination programs to prepare the opportunity of analyzing all the possible hybrid schemes, in case of the cost and thermodynamic.

\section{References}

1. A. Naeimi, V.A. Rasokhin, Scientific and technical statements of SPbPU 4 (207), 71 (2014) 
2. A. Naeimi, V. A. Rasokhin, Scientific and technical statements of SPbPU 2 (55), 58 (2017)

3. D. Zhe, L. Miao, H. Xiaojin, Zh. Yajun, Zh. Zuoyi, D. Yujie, Desalination 456121 (2019)

4. Y.M. Noura, F.G. Ahmed, Desalination 406, 37 (2017)

5. TECDOC, IAEA,

https://pub.iaea.org/MTCD/publications/PDF/te_123 5_prn.pdf (2001)

6. The economics of nuclear power, http://www.worldnuclear.org/information-library/economicaspects/economicsof-nuclear power.aspx (2017)

7. TECDOC, IAEA, Technical and Economic Evaluation of Potable Water Production Through Desalination of Seawater by Using Nuclear Energy and Other Means, http://iaea.org/inis/collection /NCLCollectionStore/_Public/24/007/24007848.pdf (1992)

8. TECDOC, IAEA, Examining the Economics of Seawater Desalination Using the DEEP Code, http://pub.iaea.org/MTCD/publications/PDF/te_118 6_prn.pdf (2000)

9. S. Dincer, I. Dincer, Energetic and Environmental Dimensions 2.20, 569 (2018)

10. A. Al-Othman, N. N. Darwish, M. Qasim, M. Tawalbeh, A. Naif, D.N. Hilal, Desalination 457, 39 (2019)

11. S. Ud-Din Khan, S. Ud-Din Khan, S. Haider, A. ElLeathy, U. Ali Rana, S. N. Danish, R. Ullah, Desalination 406, 51 (2017)

12. TECDOC, IAEA, Examining the Economics of Seawater Desalination Using the DEEP Code, http://pub.iaea.org/MTCD/publications/PDF/te_118 6_prn.pdf (2000)

13. IRENA, Report, http://www.irena.org/DocumentDo wnloads/Publications/IRENA_Water_Energy_Food _Nexus_pdf 2015 (2015)

14. O.M.A. Al-hotmani, M.A. Al-Obaidi, R. Patel, I.M. Mujtaba, Desalination 470, 59 (2019)

15. E.A. Sokolova, E.D. Fedorovich, K. Sadeghi, S.H. Ghazaie, M. V. Konushin, CYSENI, 1822 (2019)

16. A. I. Ivanov, Preparation and desalination of water with the help of Renewable Energy Sources in Russia, Crimea peninsula (SPBPU, St. Peterburg, 2017)

17. A. Al-Othman, M. Tawalbeh, M. El Haj Assad, T. Alkayyali, A. Eisa, Desalination 443, 237 (2018)

18. R. V. Andreev, Scientific and Technical Journal SPBPU, 4 (207), 49 (2014)

19. M. R. Petritchenko, N. S. Kharkov, D. V. Nemova, Scientific and Technical Journal SPBPU 4 (207), 26 (2014) 